\title{
Positive "alveolar" responses to antigen inhalation provocation tests: their validity and recognition
}

\author{
DAVID J HENDRICK, ROBERT MARSHALL, JENNIFER A FAUX, AND JOHN M KRALL \\ From the Department of Chest Diseases, Churchill Hospital and Radcliffe Infirmary, \\ Oxford University, Oxford, and the Departments of Medicine and Community Medicine, \\ West Virginia University Medical Center, Morgantown, USA
}

ABSTRACT The validity of inhalation tests in the investigation of extrinsic allergic alveolitis was assessed from the results of 144 antigen and control tests in 31 subjects. A definitive pattern of positive late responses was observed. Reactions to nebulised bird serum and droppings in subjects with bird fancier's lung were identical to reactions after "natural" exposures in aviaries or lofts, and to reactions after "occupational" challenges in subjects with farmer's lung and mushroom worker's lung. In general, positive tests were easily recognised subjectively from symptoms and signs appropriate to an influenza-like illness and undue respiratory effort on exercise. They were associated with significant changes in six readily available objective monitoring measurements-exercise minute ventilation $(\geqslant+15 \%)$, body temperature $\left(>37 \cdot 2^{\circ} \mathrm{C}\right)$, circulating neutrophils $\left(\geqslant+2500 / \mathrm{mm}^{3}\right)$, exercise respiratory frequency $(\geqslant+25 \%)$, circulating lymphocytes $\left(\geqslant-500 / \mathrm{mm}^{3}\right.$ with lymphopenia), and forced vital capacity $(\geqslant-15 \%)$. These confirmatory monitoring tests had specificities of approximately $95 \%$ and sensitivities of $85-48 \%$. Measurement of diffusing capacity, lung volume subdivisions, or resting minute ventilation/respiratory frequency proved to be too insensitive to be useful, as did auscultation and chest radiography. We conclude that responses that do provoke significant changes in these less sensitive tests are unnecessarily distressing and, presumably, unnecessarily hazardous.

The relevance of an environmental antigen to the development of diffuse alveolar disease consistent with extrinsic allergic alveolitis (EAA) is most usefully assessed from a careful clinical history. Confirmatory investigations conventionally depend on serological methods-particularly gel diffusion precipitin tests. ${ }^{1-9}$ While such tests usually demonstrate the presence of precipitating antibody if the antigen in question is indeed responsible for the disease, this is not always the case. ${ }^{7-12}$ Conversely, relatively high proportions of subjects similarly exposed, but apparently unaffected, may also give positive serological results. ${ }^{13-17}$ The antibody response may consequently reflect exposure more than disease. ${ }^{18} 19$ As yet no laboratory test has proved capable of distinguishing all affected sub-

Presented to the joint meeting of the British and American Thoracic Societies in London, January 1979.

Address for reprint requests: Dr DJ Hendrick, Tulane University School of Medicine, Pulmonary Diseases Section, 1700 Perdido St, New Orleans, Louisiana 70112, USA. jects from all who are unaffected, and in an appreciable proportion of cases a definitive diagnosis cannot be made from the clinical and laboratory features alone. This proportion includes, in particular, cases of chronic EAA where experimental periods of antigen avoidance may produce negligible improvement, cases where experimental antigen avoidance is resisted by the subject (or employer) concerned, and cases where a hitherto unrecognised agent is suspected of provoking the disease.

Where diagnostic uncertainty does persist, many specialised centres proceed to inhalation provocation tests. A response is considered to be positive if it reproduces the acute clinical manifestations of EAA. Unfortunately these acute manifestations lack specificity. Influenza-like symptoms of malaise, fever, headache, widespread muscle aching, and anorexia usually mask any evidence of a specifically pulmonary response, although breathlessness and cough may occur. 
Since the provoking agents used in these tests are commonly derived from mouldy vegetation, avian sera or excreta, or contaminated water from cooling systems or humidifiers, the significance of such systemic disturbances may be questioned. This is particularly true of those patients with the chronic form of EAA, which is not characterised by these systemic features.

Regardless of the validity of inhalation provocation tests in the investigation of EAA, there are at present no generally accepted criteria that define positive "alveolar" responses. In some studies the development of fever alone has been considered acceptable confirmatory evidence, ${ }^{520}$ while in others fever occurred in control subjects. ${ }^{2}$ Although influenza-like symptoms are the most prominent feature of positive reactions, they are not always reported. Eyckmans and colleagues ${ }^{21}$ and Scadding ${ }^{22} 23$ each described a challenge test with pigeon serum which appeared to provoke fever and leucocytosis. No other features were recorded and yet in the former case pigeon breeder's lung (PBL) was considered to be confirmed, while in the latter Scadding considered PBL improbable.

Objective measurements of pulmonary function have not been reported consistently, probably because significant changes are not always observed. The characteristic findings associated with positive alveolar reactions are restriction of ventilation (occasionally with airways obstruction) and decreased diffusing capacity for carbon monoxide (DLCO), ${ }^{254-28}$ but both ventilation and DLco may remain apparently unchanged. ${ }^{5} 29$ Gravity dependent crackles may develop, but are not commonly reported, ${ }^{27}$ 29-31 and very few investigators have recorded data regarding the monitoring value of chest radiography. ${ }^{29} 31$

The purposes of this study were to examine the characteristics and the validity of "alveolar" responses to antigen provocation tests, and to evaluate the potential roles of a number of relatively simple and readily available tests in their recognition.

\section{Subjects and methods}

Sequential inhalation provocation tests were completed in 29 subjects in whom EAA was suspected, and in two control subjects (two of us) so that a definitive result considered to confirm or exclude EAA was obtained. In six of these subjects there was already convincing evidence of EAA from the histories, physical examinations, chest radiographs, lung function studies, precipitin tests, and clinical courses after antigen avoidance. Wi the remaining subjects the evidence was not cot clusive. The majority of the subjects studied we exposed domestically to budgerigars (known parakeets in North America), pigeons, canarien, or poultry and were possibly affected by bi fancier's lung (BFL). In four subjects farmer?s lung or mushroom worker's lung was suspected $\vec{?}$

Most subjects were investigated as outpatient $\vec{s}$ with intervals of a week or so between tests. Somw were admitted to hospital and had tests on com secutive days, though usually not more than two antigen challenges were carried out during and one admission. Informed consent was obtaineid from the subjects and the protocol was approvert by the hospital ethical committee.

INHALATION PROVOCATION TESTS

Nebulised avian antigens were inhaled througe a face mask and delivered via a Wright nebulisef from two sources: avian serum (dilutions of $1 / 10000$ $1 / 5$ in carbol-saline) for 5-30 minutes, and extracts of avian droppings $(3-40 \mathrm{mg} / \mathrm{ml}$ in carbol-salines for 5-30 minutes. ${ }^{32}$

Before each test a modified skin prick test ${ }^{33}$ was performed to identify subjects at risk of develop? ing severe immediate hypersensitivity responses? No such subjects were found.

Sequential tests, involving approximately five fold increments in antigen dose, were carried ou until either an unequivocally positive response was obtained or the maximum dose (avian serur $1 / 5$ nebulising $0.5-1.0 \mathrm{ml}$ of neat serum) had pros duced no response. We believe this dose is roughl equivalent to 24 hours natural exposure in an av ary or loft of approximately 100 birds. $^{32}$ Failure to. respond at this level was deemed to exclude BFL.

The challenge exposures were carried out in 3 specially designed cabinet. In general, the fu伊 exposure of each test was undertaken in threo periods of increasing length separated by interval of 5-10 minutes. This further reduced the risk of any undue immediate reaction. Control tests were performed under identical conditions at some point or points in the series using nebulised carbol-saline alone. The identity of each test extract was nof revealed to the subject until the whole series of tests was completed. The colour of each extracto? which might have aided its identification, waso concealed by the use of a blindfold.

Natural exposure tests with avian antigens were carried out in a budgerigar aviary and in twoD pigeon lofts of local breeders. Two farm workers and one mushroom worker produced samples of the hay, straw, and mushroom compost respecto 
ively involved, and disturbed these in the challenge cabinet environment. One other mushroom worker simply returned to work under our supervision. The duration of natural exposures varied from 10 minutes to five hours.

\section{MONITORING TESTS}

Immediately before each challenge, subjects were questioned about current symptoms and underwent routine examination of the chest. Challenges were carried out during the morning, usually between 0800 and 1000 hours. Subjects were seen at frequent intervals during the next 36 hours, or until any positive response subsided, and any unusual symptoms were recorded. Monitoring investigations were carried out immediately before challenge and were repeated at least once later the same day, usually between 1600 and 1930 hours. In the event of a positive response, the timing of repeated investigations was influenced by the time at which symptoms reached their peak.

Oral temperature was measured immediately before each exercise test (see below) and at hourly intervals throughout the day.

Venous blood was taken immediately before each exercise test. Total leucocyte counts were measured in a Coulter counter, evening samples being tested the next morning after storage in a refrigerator. Smears were made from freshly taken blood for differential cell counts.

Pre-challenge pulmonary function studies included measurement of forced expiratory volume in one second $\left(\mathrm{FEV}_{1}\right)$ and forced vital capacity (FVC) using a dry Vitalograph spirometer and, during the earlier part of the study, measurement of DLco by the single breath method ${ }^{34}$ and the subdivisions of lung volume by the helium dilution technique ${ }^{35}$ Most patients learned to use the Vitalograph spirometer themselves, and so were able to record tracings at hourly intervals. In general, two or three tracings were made on each occasion, the one recording the greatest FVC being chosen for analysis.

Because early "positive" tests induced increased breathlessness on exertion which was not associated with significant changes in resting lung function nor with appreciable breathlessness at rest, a simple test of lung function during exercise was devised. This consisted of measurement of minute volume and respiratory frequency during three consecutive five-minute periods: sitting at rest; walking on a level treadmill at a comfortable constant rate (one to three miles per hour according to individual ability, and identical in all subsequent tests); sitting during recovery. The minute volume was measured by breathing from a dry gas meter, and the frequency was recorded by a pneumotachygraph in the breathing circuit.

The significance of objective changes associated with positive antigen tests was assessed by comparison (a) of positive antigen tests with paired control tests in the same subjects, and (b) of positive antigen tests with similar antigen tests in the subjects shown to be non-reactors. The paired comparisons (a) were tested statistically with a paired $t$ test in the case of body temperature and FVC, and Wilcoxon signed ranks tests in the case of neutrophil and lymphocyte counts, exercise minute volume, and exercise respiratory frequency. Comparisons between antigen tests (b) were made with a two-sample $t$ test for body temperature and FVC, and with Mann-Whitney $U$ tests for the other measurements. ${ }^{36}$

\section{Results}

One hundred and forty-four inhalation provocation tests involving 31 subjects were completed satisfactorily. The result of each test was judged at the time as positive, equivocal, or negative. Positive tests were defined from two standpoints. Firstly, the subjects concerned developed symptoms of sufficient degree to convince them that they were directly provoked by the earlier challenges despite their not knowing whether the nebulised challenges involved antigen or control exposures. Secondly, we the observers were also convinced of the positive nature of the test, taking into account not only the character and timing of the symptoms described, but also the physical signs, and the responses to any earlier provocation tests. When either party was not fully convinced, though suspicious, the result was defined as equivocal. When neither party was suspicious, the result was deemed negative.

Fifteen antigen challenges provoked equivocal results. Fourteen of these occurred in seven subjects who gave unequivocally positive results after further challenges with the same or higher doses of antigen. In the remaining subject, further antigen challenge produced negative results.

A diagnosis of EAA (with respect to the antigen investigated) was considered to be confirmed in those subjects giving unequivocally positive responses-"reactors"- and to be excluded in those who failed to respond in this manner after completing the full series of tests-"non-reactors". The two control subjects both proved to be nonreactors, and the six subjects who already showed "convincing evidence" of EAA all proved to be 
reactors. An analysis of the results is given in table 1 . Positive responses after each type of antigenic challenge were indistinguishable.

The result category of each test and the reactor status of each subject were consequently determined at the time of the challenge studies without regard to the objective monitoring parameters. The relative merit of each potential monitoring test was then assessed by comparing the changes associated with positive and obligatorily negative tests (all control tests, and all antigen tests in the non-reactors).

\section{MONITORING TESTS}

Symptoms

Tests associated with the development of charace teristic symptoms that the subjects regarded ass definite are recorded in table 2. Influenza-lik@ symptoms predominated-malaise, fever, wides spread aches and pains (particularly headache), anorexia-and occurred with all positive reactions. Respiratory symptoms were less striking. Few subjects were troubled by undue breathlessness aפ rest, though all noted this on exertion-particus larly during the exercise test. Several also develis

Table 1 Analysis of "alveolar" responses to 144 inhalation provocation tests in 31 subjects

\begin{tabular}{|c|c|c|c|c|c|c|c|c|c|c|c|}
\hline \multirow[t]{3}{*}{ Subjects } & \multirow{3}{*}{$\begin{array}{l}\text { Antigen } \\
\text { source }\end{array}$} & \multicolumn{10}{|c|}{ Challenge exposure and test result } \\
\hline & & \multirow[t]{2}{*}{ Control } & \multicolumn{3}{|c|}{$\operatorname{Serum}(m l)$} & \multicolumn{3}{|c|}{ Droppings $(m g)$} & \multicolumn{3}{|c|}{ Natural (hours) } \\
\hline & & & $<0 \cdot 1$ & $0 \cdot 1-0 \cdot 5$ & $\geqslant 0.5$ & $<10$ & $10-50$ & $\geqslant 50$ & $<1$ & $1-5$ & $\geqslant 5 \overline{\mathbb{D}}$ \\
\hline \multirow{2}{*}{\multicolumn{12}{|c|}{$\begin{array}{c}\text { Reactors } \\
\text { Avian }\end{array}$}} \\
\hline & & & & & & & & & & & $\infty$ \\
\hline${ }_{2}^{1 \dagger}$ & B & $\mathbf{N}$ & $\begin{array}{l}\mathbf{P} \\
\mathbf{N}\end{array}$ & $\mathbf{N}$ & & & & & & & . \\
\hline $\begin{array}{l}2 \\
3\end{array}$ & $\begin{array}{l}\mathbf{B} \\
\mathbf{B}\end{array}$ & $\begin{array}{l}\mathbf{N} \\
\mathbf{N}\end{array}$ & $\mathbf{N}$ & $\begin{array}{l}\mathbf{N} \\
\text { NEE }\end{array}$ & $\mathbf{P}$ & & & & & $\mathbf{N}$ & EP \\
\hline $4 \dagger$ & $\begin{array}{l}\mathbf{B} \\
\mathbf{P}\end{array}$ & $\mathbf{N}$ & NN & $\mathbf{P}$ & & & & & & $\begin{array}{l}\mathbf{N} \\
\mathbf{P}\end{array}$ & EPQ \\
\hline 5 & $\begin{array}{l}\text { B } \\
\text { C }\end{array}$ & NNN & E & $\mathbf{N}^{*}$ & $\mathbf{E}$ & & & & & EP & う \\
\hline 6 & B & $\mathbf{N}$ & $\mathbf{N}$ & $\begin{array}{l}\mathbf{P} \\
\mathbf{N}\end{array}$ & $\mathbf{P}$ & & & & & & బ్రి \\
\hline 7 & B & $\mathbf{N}$ & $\mathbf{N}$ & PP & & & & & & NN & 음 \\
\hline 8 & B & $\mathbf{N}$ & & & & $\mathbf{N}$ & $\mathbf{E}$ & $\mathbf{P}$ & & $\mathbf{P}$ & 气 \\
\hline $9 \dagger$ & B & $\mathbf{N}$ & $\mathbf{N}$ & NP & & $\mathbf{N}$ & & & & $\mathbf{P}$ & $\overrightarrow{\bar{O}}$ \\
\hline 10 & B & NNNN & $\mathbf{E}$ & EE & $\mathbf{N} * \mathbf{P}$ & & & & & $\mathbf{E}$ & 3 \\
\hline & $\mathbf{Y}$ & & $\mathbf{N}$ & $\mathbf{N}$ & & & & & & & $\bar{z}$ \\
\hline $\begin{array}{l}11 \dagger \\
12\end{array}$ & B & $\begin{array}{l}\mathbf{N} \\
\mathbf{N}\end{array}$ & EP & & & & & & & & 蟢 \\
\hline $\begin{array}{l}12 \\
13\end{array}$ & $\begin{array}{l}\mathbf{B} \\
\mathbf{B}\end{array}$ & $\begin{array}{l}\mathbf{N} \\
\mathbf{N N}\end{array}$ & $\mathbf{N}$ & NN & $\mathbf{P}$ & & & & $\mathbf{N}$ & $\mathbf{P}$ & $\stackrel{0}{*}$ \\
\hline $\begin{array}{l}13 \\
14\end{array}$ & $\begin{array}{l}\mathbf{B} \\
\mathbf{B}\end{array}$ & $\begin{array}{l}\mathbf{N N} \\
\mathbf{N}\end{array}$ & $\mathbf{P}$ & & & & & & & $\mathbf{E}$ & ફ \\
\hline $15 t$ & $\mathbf{P}$ & $\mathbf{N}$ & $\mathbf{N}$ & $\mathbf{N}$ & $\mathbf{P}$ & & & & E & & 으 \\
\hline \multicolumn{12}{|l|}{ Non-avian } \\
\hline 16 & $\mathbf{H}$ & $\mathbf{N}$ & & & & & & & & $\mathbf{P}$ & б \\
\hline $17 \dagger$ & $\mathbf{F}$ & $\mathbf{N}$ & & & & & & & & $\mathbf{P}$ & 3 \\
\hline 18 & $\mathbf{S}$ & $\mathbf{N}$ & & & & & & & $\mathbf{P}$ & & i) \\
\hline \multirow{2}{*}{\multicolumn{12}{|c|}{$\begin{array}{l}\text { Non-reactors } \\
\text { Avian }\end{array}$}} \\
\hline & & & & & & & & & & & \\
\hline $\begin{array}{l}19 \\
20\end{array}$ & $\begin{array}{l}\mathbf{P} \\
\mathbf{B}\end{array}$ & $\mathbf{N}$ & $\mathbf{N}$ & $\mathbf{N}$ & $\mathbf{N}$ & & & & & & 옥 \\
\hline $\begin{array}{l}20 \\
21\end{array}$ & $\begin{array}{l}\text { B } \\
\mathbf{B}\end{array}$ & $\mathbf{N}$ & & $\mathbf{N}$ & $\mathbf{N}$ & & NN & & & NN & $D$ \\
\hline $\begin{array}{l}21 \\
22\end{array}$ & $\begin{array}{l}\text { B } \\
\mathbf{B}\end{array}$ & $\mathbf{N}$ & $\mathbf{N}$ & $\mathbf{N}$ & $\mathbf{N}$ & & & & & & $\frac{1}{2}$ \\
\hline 23 & $\begin{array}{l}\text { B } \\
\mathbf{B}\end{array}$ & $\begin{array}{l}\mathbf{N} \\
\mathbf{N}\end{array}$ & $\begin{array}{l}\mathbf{N} \\
\mathbf{N}\end{array}$ & $\begin{array}{l}\mathbf{N} \\
\mathbf{N}\end{array}$ & $\begin{array}{l}\mathbf{N} \\
\mathbf{N}\end{array}$ & & & & & & 三. \\
\hline 24 & B & & $\mathbf{N}$ & $\mathbf{N}$ & $\mathbf{N}$ & & & & & $\mathbf{N}$ & న \\
\hline & $\mathbf{P}$ & & & & & & & & $\mathbf{P}$ & & \\
\hline 25 & B & $\mathbf{N}$ & $\mathbf{N}$ & $\mathbf{N}$ & $\mathbf{N}$ & & & & & & 요 \\
\hline 26 & B & $\mathbf{N}$ & & $\mathbf{N}$ & $\mathbf{N}$ & & & & & $\mathbf{N}$ & $\omega$ \\
\hline $\begin{array}{l}27 \\
28\end{array}$ & $\begin{array}{l}\mathbf{B} \\
\mathbf{B}\end{array}$ & $\mathbf{N}$ & $\mathbf{N}$ & $\mathbf{N}$ & $\begin{array}{l}\mathbf{N} \\
\mathbf{N}\end{array}$ & $\mathbf{N}$ & $\mathbf{N}$ & $\mathbf{N}$ & & IV & $\sigma$ \\
\hline 29 & B & & & $\mathbf{N N}$ & $\mathbf{N}$ & & & & & & \\
\hline 30 & B & $\mathbf{N}$ & $\mathbf{N}$ & $\mathbf{N}$ & $\mathbf{N}$ & $\mathbf{N}$ & $\mathbf{N}$ & EN & & & 읃 \\
\hline Non-avian & & & & & & & & & & & $\mathbb{D}$ \\
\hline 31 & $\mathbf{M}$ & & & & & & & & $\mathbf{N}$ & NN & \\
\hline
\end{tabular}

$\mathrm{B}=$ budgerigar, $\mathrm{C}=$ canary, $\mathrm{F}=$ mushroom farm, $\mathrm{H}=$ hay, $\mathrm{M}=$ mushroom compost, $\mathrm{P}=$ pigeon, $\mathrm{S}=\mathrm{straw}, \mathrm{Y}=$ poultry, $\mathrm{N}=$ negative, $\mathrm{E}=\mathrm{equivoc} \bar{\Phi}$ $\mathbf{P}=$ positive.

*These two discordant "negative" results were obtained in two subjects who gave consistently weak responses to antigen challenge irrespective the challenge dose. One test was carried out on the day immediately after an "equivocal" response, and this may have exhausted the limited respor siveness of the subject concerned. The other subject gave responses that did not reach their peaks until the day after challenge. This was not appreci ated at the time of this anomalous test, and no subjective data were recorded for the relevant following day. The test did nonetheless produce an objective monitoring score of $2 / 6$ (see text below).

†Subjects who already showed "convincing evidence" of EAA before challenge. 
Table 2 Distribution of symptoms and clinical signs developing during the 36 hours after challenge, according to result category

\begin{tabular}{|c|c|c|c|c|c|}
\hline \multirow[t]{3}{*}{ Result category } & \multirow[t]{3}{*}{ Tests } & \multicolumn{4}{|c|}{ Number of test ${ }^{*}$ associated with } \\
\hline & & \multicolumn{2}{|c|}{ Symptoms } & \multicolumn{2}{|c|}{ Clinical signs } \\
\hline & & Flu-like & $\begin{array}{l}\text { Dysp- } \\
\text { noea }\end{array}$ & Appearance & Breathing \\
\hline \multicolumn{6}{|l|}{ Reactors $(n=18)$} \\
\hline $\begin{array}{l}\text { Antigen tests } \\
\text { Positive }\end{array}$ & \multicolumn{5}{|c|}{ Antigen tests } \\
\hline Equivocal & 14 & 11 & 12 & $3 / 13$ & $3 / 10$ \\
\hline Negative & 25 & 0 & 1 & & 0 \\
\hline Control tests & 24 & 0 & 2 & $0 / 23$ & $0 / 23$ \\
\hline \multicolumn{6}{|c|}{ Non-reactors $(n=13)$} \\
\hline Antigen tests & 49 & $\mathbf{0}$ & 3 & $\mathbf{0}$ & 1 \\
\hline Control tests & 9 & $\mathbf{0}$ & 0 & $\mathbf{0}$ & $\mathbf{0}$ \\
\hline
\end{tabular}

*Tests were excluded from tables $2-4$ and figures 1 and 4 whenever the records were incomplete. Corrected totals are given where appropriate.

oped a dry cough and difficulty taking a deep satisfying breath, but none felt wheezy. In addition, three reactors developed nausea (one with vomiting) and two others diarrhoea.

In all but three subjects, symptoms began after two to nine hours and reached maximum intensities after between six and 20 hours of the start of exposure. In one subject with farmer's lung, symptoms began after about one hour, while in two avian reactors the onset of symptoms was delayed for 12-18 hours after the start of exposure. With both these avian reactors the maximum intensity of the symptoms experienced was not reached until the next day. All positive reactions were consequently of the "late" type, and all persisted for a minimum of several hours.

\section{Clinical signs}

Table 2 gives the distribution of characteristic clinical signs that the observers regarded as definite, according to result category. Facial appearance proved to be the most informative clinical sign and the observers soon learned to recognise the onset of positive responses from the loss of normally cheerful and active expressions. At this stage the subjects themselves rarely admitted to any change in well-being. As the response worsened, an unwell appearance was generally readily apparent. Increased respiratory effort on exercise during the symptomatic phase of positive tests was usually obvious, but this was rarely true at rest.

Auscultatory signs were uncommon. In five patients relatively strong reactions were associated with the development of fine inspiratory crackles in the lung bases. In four patients, basal crackles noted before challenge seemed to become more extensive, and in three others crackles appeared to develop at the extreme lung bases, but these were not consistently heard. No subject developed wheezes.

\section{Body temperature}

Fever characteristically accompanied positive reactions and was usually symptomatic. The mean changes in body temperature according to result category are givèn in table 3 .

Table 3 Mean maximum body temperatures during the 36 hours after challenge, according to result category

\begin{tabular}{lllll}
\hline Result category & Tests & \multicolumn{2}{l}{$\begin{array}{l}\text { Mean temperature }\left({ }^{\circ} \mathrm{C}\right) \text { per subject } \\
\text { before and after challenge }\end{array}$} \\
\cline { 3 - 5 } & & Before & After & Change \\
\hline Reactors $(n=18)$ & & & & \\
Antigen tests & 23 & 36.5 & 37.9 & +1.4 \\
$\quad \begin{array}{l}\text { Positive } \\
\text { Equivocal }\end{array}$ & 14 & 36.5 & 36.8 & +0.3 \\
$\quad$ Negative & 22 & 36.5 & 36.7 & +0.2 \\
Control tests & 22 & 36.5 & 36.7 & +0.2 \\
Non-reactors $(n=13)$ & & & & \\
Antigen tests & 47 & 36.3 & 36.7 & +0.4 \\
Control tests & 8 & 36.3 & 36.7 & +0.4 \\
\hline
\end{tabular}

*Because individual subjects underwent different numbers of tests, mean values for each subject are used in tables 3 and 4 . Each subject consequently influenced the results to an equal degree.

The results obtained from positive tests in the reactors cannot be compared in a strict statistical sense with those from the negative antigen tests in the non-reactors because different challenge exposures were used. By considering challenges using budgerigar serum (BS) alone, the significance of any differences was evaluated more satisfactorily. A subgroup of challenge tests was selected comprising all positive tests to BS (10 tests in nine reactors-mean nebulised dose, $0.38 \mathrm{ml}$ neat BS), and all tests to high dose BS in non-reactors (11 tests in 11 non-reactors-mean nebulised dose, $0.75 \mathrm{ml}$ neat BS). These were the tests that had determined whether each budgerigar fancier was a reactor or non-reactor, respectively. Data from these selected tests and the corresponding control tests showed almost identical mean changes to those obtained overall (reactors: positive tests $+1.5^{\circ} \mathrm{C}$ versus control tests $+0.3^{\circ} \mathrm{C}, \mathrm{p}<0.01$; antigen tests: reactors $+1.5^{\circ} \mathrm{C}$ versus non-reactors $\left.+0.4^{\circ} \mathrm{C}, \mathrm{p}<0.01\right)$. This confirmed that the increase in body temperature associated with positive tests was of a statistically significant degree.

Figure 1 compares the distributions of maximum body temperatures after positive and obligatorily negative tests. Measurements of $37.2{ }^{\circ} \mathrm{C}$ or less were obtained with $95 \%(73 / 77)$ of the obligatorily negative tests, while measurements exceeding 

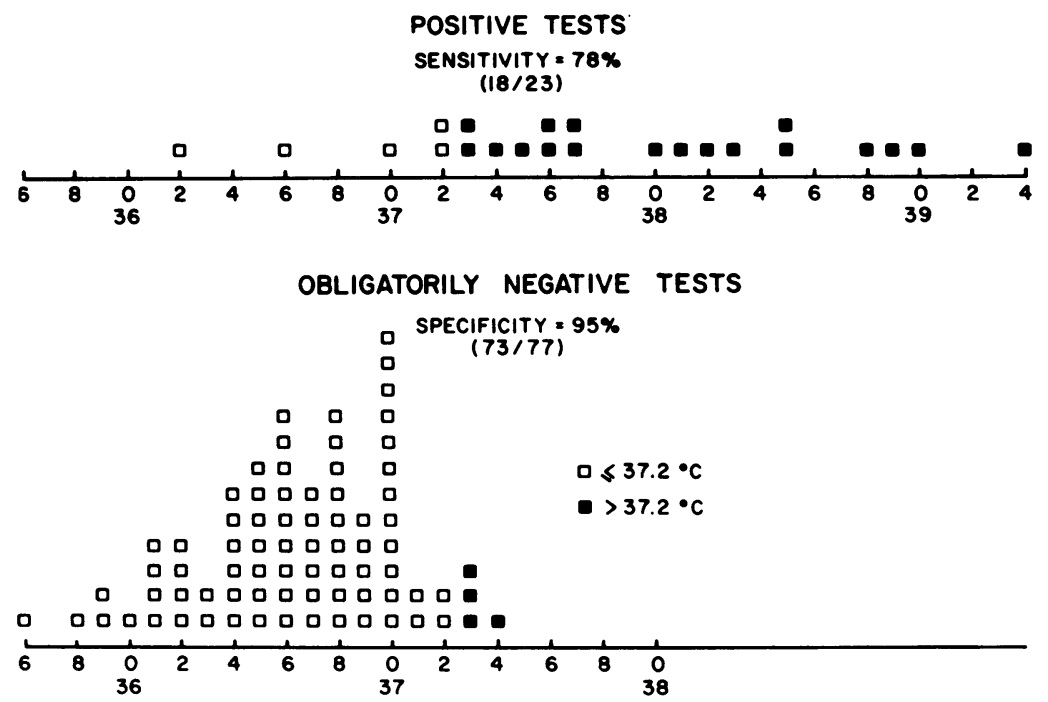

Fig 1 Distributions of maximal body temperatures during the 36 hours after challenge.

\section{MAXIMUM BODY TEMPERATURE $\left({ }^{\circ} \mathrm{C}\right)$}

$37 \cdot 2{ }^{\circ} \mathrm{C}$ were obtained with $78 \%(18 / 23)$ of the positive tests. Body temperature exceeding $37 \cdot 2^{\circ} \mathrm{C}$ during the 36 hours after challenge was consequently a valid diagnostic feature of positive responses, having high specificity (the diagnostic end-point having been chosen to identify approximately $95 \%$ of negatives) and moderate sensitivity ( $78 \%$ of positives identified).

Leucocyte counts, exercise tests, and spirometry Data on the other objective monitoring parameters were analysed in the manner described for body temperature. Increases in circulating neutro- phil counts, exercise minute volume, and exercise respiratory frequency, and decreases in circulating lymphocyte counts and FVC were found to beo statistically significant and to have useful diag-这 nostic value (sensitivities of approximately $50 \%$ or more were obtained after choosing end-points@ that produced specificities of about $95 \%$ ). The details are summarised in table 4 . For each of these measurements, the subgroups of tests used for statistical analysis showed almost identical mean changes to those observed overall.

Marked increases in the numbers of circulating leucocytes were observed in association with

Table 4 Mean maximal changes of objective monitoring tests during the 36 hours after challenge, according to result category

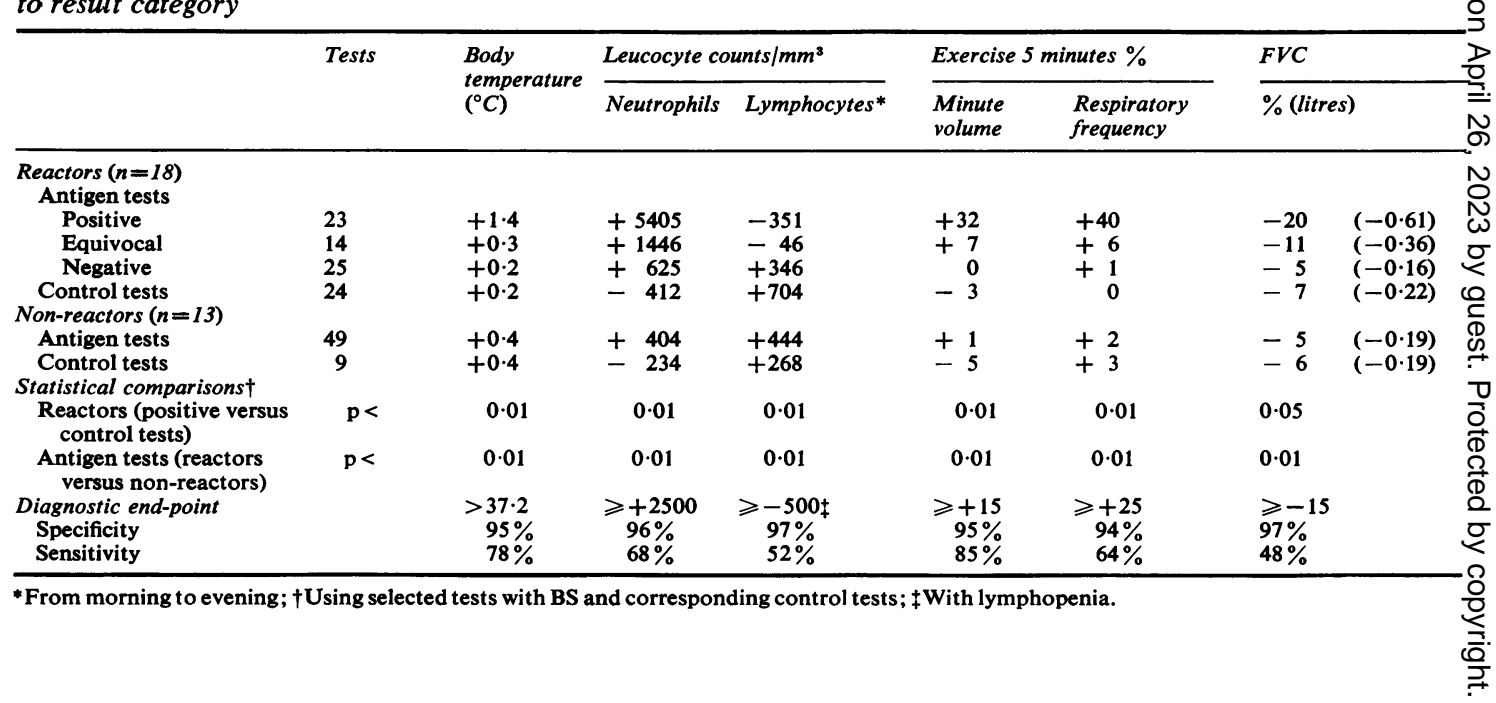


positive tests, and these changes were found to be fully attributable to increases in the neutrophil fraction. With 12 of the positive tests absolute neutrophila $\left(>7500 \text { neutrophils } / \mathrm{mm}^{3}\right)^{37} 38$ developed.

The lymphocyte counts were also affected by positive tests, though in the converse manner and to a much less marked degree. It can be seen from table 4 that the mean lymphocyte counts associated with control and negative tests increased mildly after challenge, while there was a small decrease associated with equivocal tests and a more marked decrease with positive tests. The absolute changes in lymphocyte counts did not prove to be of diagnostic value when considered alone, because there was considerable overlap between the distributions associated with positive and obligatorily negative tests. However, a decrease in lymphocyte count of 500 cells $/ \mathrm{mm}^{3}$ or more did prove to be of diagnostic value when coupled with the development or worsening of absolute lymphopenia $(<1500$ lymphocytes $\left./ \mathrm{mm}^{3}\right)^{3739}$

There were no significant changes in the numbers of circulating eosinophils.

The results of the exercise tests are expressed in terms of percentage rather than absolute changes because there were variations between the subjects in treadmill speeds and prechallenge ventilatory patterns. The exercise period, in comparison with the resting period preceding it and the recovery period succeeding it, was associated with the greatest increase after positive tests and the least change after obligatorily negative tests. Measurement of minute volume and respiratory frequency during the resting period consequently proved to be much less sensitive in distinguishing positive from obligatorily negative tests. For both tests an end-point of $\geqslant+25 \%$ produced a specificity of $94 \%$, but sensitivities were only $40 \%$ and $30 \%$ respectively. Combining data from the 10 minutes of exercise + recovery proved to be less useful than data from the exercise period alone.

With positive responses quite marked individual variations in tidal volume and respiratory rate were noted during the exercise tests, but there was no overall tendency to rapid shallow breathing. The mean tidal volume did not change significantly and calculations with an assumed anatomical dead space of $150 \mathrm{ml}$ showed a mean increase in alveolar ventilation of $30 \%$ in association with positive tests. There was a mean fall of $3 \%$ with corresponding control tests.

Similar mild mean decrements in FVC were noted with each subgroup of obligatorily negative tests. These are probably attributable to the bias of choosing the minimum of multiple measurements. The mean maximum fall in FVC of $20 \%$ after positive tests was accompanied by a similar mean maximum fall in $\mathrm{FEV}_{1}$ of $19 \%$, indicating the ventilatory disturbance produced was one of restriction, not obstruction. The mean ratio $\mathrm{FEV}_{1} /$ FVC was $81 \%$ both immediately before challenge and at the time of the maximum fall in FVC.

\section{Lung volumes}

Routine measurement of the subdivisions of lung volume after initial positive tests did not demonstrate great changes, and this practice was discontinued after paired positive and control tests were monitored in four reactors. A modest fall in inspiratory capacity (mean $-9 \%$ ) without change in functional residual capacity (mean $-1 \%$ ) was the most prominent finding associated with positive tests, though a mild reduction in expiratory reserve volume (mean $-7 \%$ ) was also noted. The vital capacity and the total lung capacity were reduced appropriately (means of $-8 \%$ and $-5 \%$ respectively), and there was a small increase in residual volume (mean $+3 \%$ ) appropriate to the reduced expiratory reserve volume and the unchanged functional residual capacity. Similar changes were observed in a further reactor in whom measurements after control challenge were not obtained.

\section{Single breath diffusing capacity}

Diffusing capacity for carbon monoxide was measured in association with 12 positive challenge tests in 10 reactors. Appreciable decreases of $14-45 \%$ ) occurred with three of the more severe reactions only. Figure 2 compares the distributions of changes in Duco after positive and obligatorily negative tests. Only decrements of $15 \%$ or more could be considered diagnostically significant, and with this end-point only two of the positive tests could be identified.

\section{Chest radiographs}

No unequivocal changes were noted in 12 inspiratory and five expiratory radiographs of 12 subjects undergoing positive responses. In six films there was some suspicion of increased haziness/ nodularity, for which technical differences may have been responsible.

\section{TOTAL MONITORING SCORE}

In assessing the diagnostic value of the various monitoring tests studied, the ability of each to identify obligatorily negative tests correctly (the specificity) was related to the converse function of identifying the unequivocally positive tests 


\section{POSITIVE TESTS}

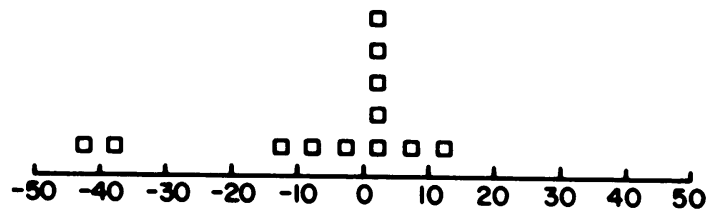

OBLIGATORILY nEgatIVE TESTS

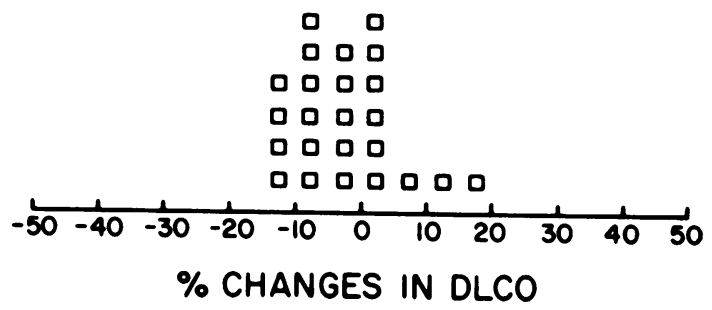

Fig 2 Distributions of percentage changes in DLCO during the 36 hours after challenge.

correctly (the sensitivity). The endpoints required to give specificities of about $95 \%$ produced useful sensitivity levels (approximately $50 \%$ or more) for 10 of the tests studied-symptoms and signs appropriate to an influenza-like illness and undue respiratory effort on exercise (the four subjective observations), and body temperature, circulating neutrophil and lymphocyte counts, exercise minute volume and respiratory frequency, and FVC (the six objective tests).

By allowing a score of one for each of these 10 tests giving diagnostically significant changes, a maximum total monitoring score of $8-10$ was possible for the overwhelming majority of tests (not all tests were used in each challenge). The mean scores per challenge test and the mean scores expressed as a percentage of the maximum

Table 5 Total monitoring scores, according to result category

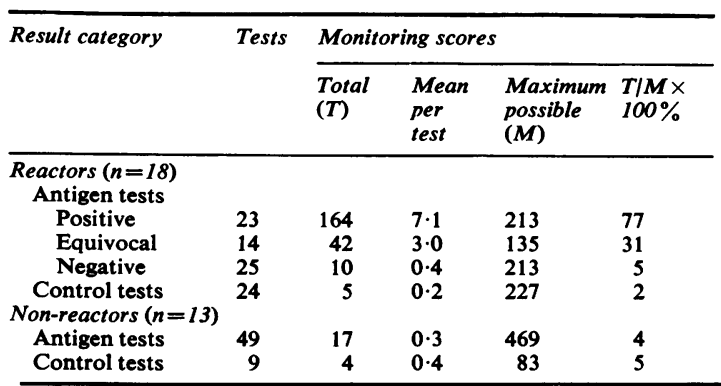

score possible are shown according to resultos category in table 5. Obligatorily negative testso showed, by design, mean scores not exceeding $5 \%$ 음 of the maximum possible, while positive tests ando equivocal tests (given by the reactors) were associ- $-\frac{\pi}{2}$ ated with mean scores of 77 and $31 \%$ respectively This total monitoring score proved to be of greater. diagnostic value than any of the individual tests? considered alone. All the positive challenge tests were associated with scores of 4 or more, whiles all the obligatorily negative tests were associated with scores of 3 or less (fig 3).

If a score of 3 or more is chosen to define positive result, a specificity of $99 \%$ is obtained.A This definition would allow eight of the $15 \overrightarrow{\mathrm{c}}$ equivocal tests to be reclassified as "positive.'? All eight had occurred in reactors.

\section{SEQUELAE}

In general the systemic response, as measured by the influenza-like symptoms, unwell appearance ${ }^{\circ}$ temperature increase, and haematological changes subsided spontaneously within one to two dayso The pulmonary response, particularly increased breathlessness on exertion and cough, sometimeș persisted longer (in one case for as much as two to three weeks), and for this reason the routine use of prednisone (commencing at $30 \mathrm{mg}$ daily and tailed off over 5-10 days) was introduced With this modification, symptoms were generally satisfactorily controlled within a day or two.

The possibility of long-term sequelae after these provocation tests was considered in 13 of the re-包 actors who were restudied after intervals rangingo from 0.5 to 33 months (mean nine months). Onlye. two considered they had deteriorated. Pulmonaryo function tests in the remainder showed that lung function had recovered to at least prechallengeo levels, and often to within the predicted normal range.

One subject improved initially when she gaven up her birds and was treated temporarily with? modest doses of corticosteroids (prednisone 20 $\mathrm{N}$ $30 \mathrm{mg}$ daily). Weight gain and increased incapacity from severe osteoarthritis soon led to reduction ino corticosteroid dosage, and her respiratory sympo toms and lung function thereafter worseneco steadily. Continuing budgerigar exposure during frequent "baby sitting" activities at her son'so home was eventually discovered.

One other subject admitted to mildly increased breathlessness on exertion when reinvestigated seven months after her positive challenge. She hado denied this during the few months immediately after it, and serial lung function studies did nof 
POSITIVE TESTS

SENSITIVITY $=100 \%$

$(23 / 23)$

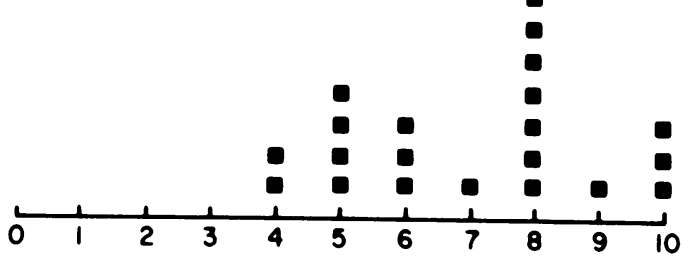

EQUIVOCAL TESTS

(IN REACTORS)

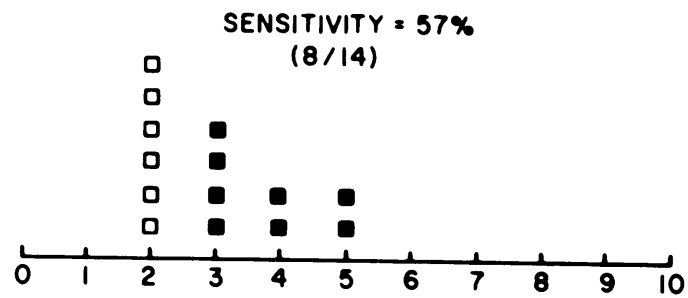

OBLIGATORILY NEgATIVE TESTS

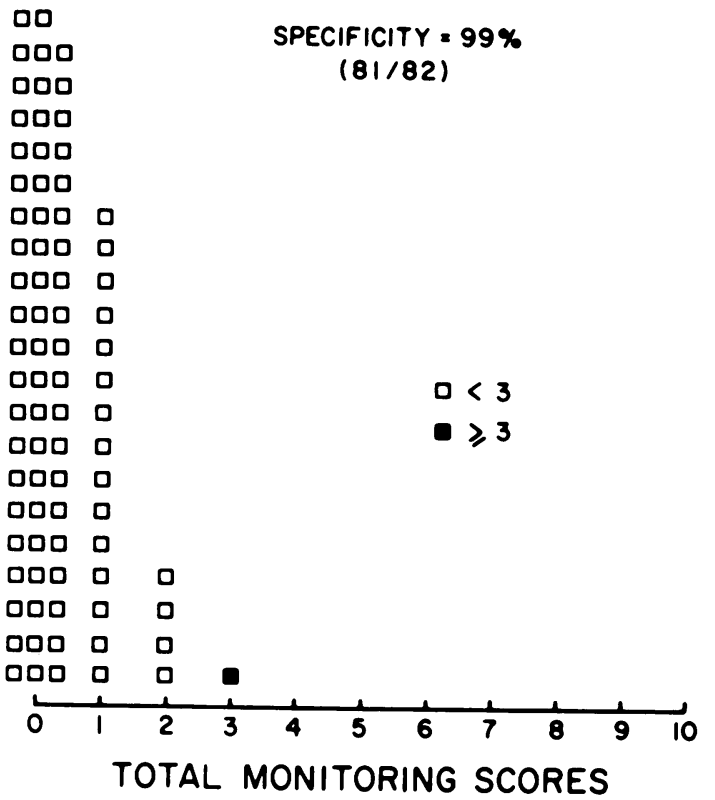

Fig 3 Distributions of total monitoring scores according to result category.

give confirmatory evidence of deteriorating lung function. It seemed probable that increasing angina of effort was the true cause of her reduced exercise tolerance.

\section{Discussion}

Although inhalation provocation tests are widely used in the investigation of allergic asthma, their role in the investigation of EAA is not well established. Extrinsic allergic alveolitis is much less common than asthma, and many of the antigens responsible have been recognised in recent years only. Experience is consequently limited. Furthermore, allergic "alveolar" reactions are of the "late" type only, and so the tests provoking them are particularly time-consuming.

A more serious problem concerns the validity of the positive "alveolar" reaction. It could be argued that a systemic response occurring without evidence of pulmonary dysfunction is caused by the presence of contaminating microbial toxins or, after challenge with bird serum, by serum sickness; that systemic hypersensitivity to the test antigen could have been induced by sequential test exposures themselves; and that, irrespective of its cause, systemic hypersensitivity could be unrelated to coexisting lung disease.

That no significant responses occurred in the two control subjects or in 11 other non-reactors, is strong evidence against toxic mechanisms being directly responsible. Positive tests were reproducible and were readily distinguished from control tests despite the identity of the nebulised challenges being unknown to the subjects concerned. Furthermore, positive responses were obtained from all six of the subjects who had already shown convincing evidence of EAA before undergoing inhalation challenge. Five of the reactors gave equivocal or positive responses to their first challenge with the relevant bird serum, confirming that in them, at least, hypersensitivity to bird serum was not a consequence of the test exposures themselves. The three subjects reacting to hay, straw, and mushroom compost respectively also gave positive responses to their first test exposure. All the postive reactions were essentially identical in nature, irrespective of the particular provoking antigen or its means of delivery, and irrespective of whether the subject concerned manifested the acute or chronic form of EAA. The responses were shown to involve significant changes in lung function, despite the dominance of systemic disturbances, and they closely resembled the acute illnesses with which the pigeon breeders and farm workers had presented. We conclude that the evidence provided by inhalation provocation tests of the type described is both valid and definitive in the investigation of EAA. No other currently available test is of equal diagnostic value. 
Subjective observations found to be useful in monitoring the alveolar response to challenge were the symptoms and corresponding clinical signs of an influenza-like illness and undue shortness of breath on exercise. All proved to be highly discriminatory, especially when they were considered together. Their significance was limited, however, because they were largely responsible for establishing the result category initially. In this respect the objective parameters were more valuable, since the objective data were not analysed until the study had been completed and the result of each test had been defined. Six objective measurements showed statistically significant changes in association with positive tests. Overall, they were less sensitive than the subjective observations but they confirmed that significant systemic and pulmonary changes occurred only in the reactors, and only after antigen challenges. This validates the use of the subjective parameters in establishing the result category.

Measurement of minute volume during the exercise period of the exercise test proved to be the most useful objective parameter, having a sensitivity of $85 \%$ (fig 4). This depended to some extent on performing sequential exercise tests after challenge so that maximal changes could be identified. The latter were found to coincide with $\underset{\vec{\rho}}{\vec{\rho}}$ the symptomatic peaks of positive reactions.

Measurement of exercise respiratory frequency proved to be less sensitive than minute volume but $\frac{\rho}{\vec{D}}$ was, nevertheless, more useful than any of the $\mathbb{Q}$ other tests of pulmonary function. Increased exer- \& cise respiratory frequency may have been partly $\vec{A}$ dependent on the commonly accompanying pyrexia, though pyrexia appeared to have negligible $\vec{\omega}$ effect on exercise minute volume during heat challenge experiments involving the two control $\underset{x}{x}$ subjects and a well-insulated electrically heated of suit. These divergent effects of fever on respiration $\sigma$ have been described by Petersen and Vejby- $A$ Christensen. ${ }^{40}$ In fact, at the times of the relevant $\mathrm{G}$

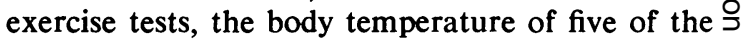
reactors did not exceed $37 \cdot 0^{\circ} \mathrm{C}$.

Measurements made during the initial resting and subsequent recovery periods of the exercise $\Phi$ tests did not in any combination improve the $\overrightarrow{0}$ diagnostic value of the exercise period alone. The $\stackrel{0}{\circ}$ exercise test as described could consequently be simplified by omitting these two unhelpful periods, and by performing a single follow-up study when any symptoms appear to be maximal.

The exercise test changes were found to be the $\frac{\circ}{\mathbb{D}}$ result of increased alveolar ventilation. It is of

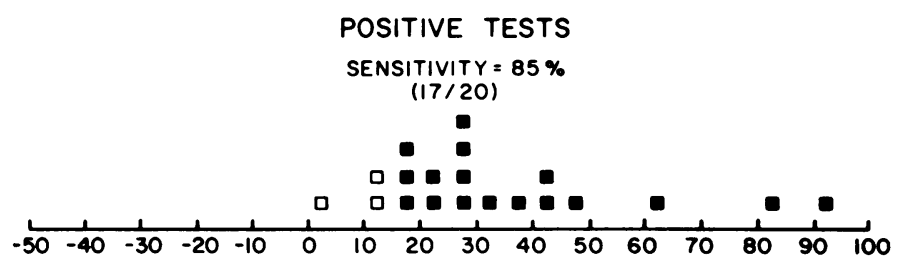

OBLIGATORILY NEGATIVE TESTS

口 SPECIFICITY $=95 \%$

a $(74 / 78)$

口

0

00

व व

व 0

व व

व 0 व

व

व व व

व

व व व

व व व व

व व व

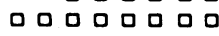

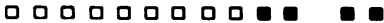

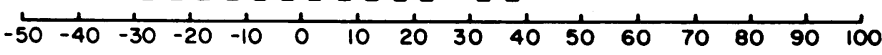

$\%$ CHANGES IN EXERCISE MINUTE VOLUME
Fig 4 Distributions of maximal percentage changes in exercise minute volume during the 36 hours after challenge. 
some interest that this usually occurred in the absence of a significant reduction in DLco. Hyperventilation and decreased arterial $\mathrm{PCO}_{2}$ are characteristic of more advanced stages of both cryptogenic fibrosing alveolitis and EAA, and it is probable that hyperventilation rather than large increases in physiological dead space was responsible. It may be that relatively modest diffuse alveolar insults provoke increased sensitivity of afferent nerve endings and hence hyperventilation, when the degree of any alveolar ventilation/perfusion imbalance is insufficient to impair carbon monoxide transfer. This may also occur before there is a significant decrease in compliance. ${ }^{41-43}$

The usefulness of the exercise test in demonstrating pulmonary involvement in the reactions observed may be seen in perspective by considering the other tests monitoring lung function which were all measured at rest. Only the repeated measurement of FVC proved to be worthwhile but its sensitivity was less than $50 \%$. Warren and colleagues used flow volume loops and single breath nitrogen washout curves to monitor changes in lung function during positive "alveolar" responses of six patients with bird fancier's lung. ${ }^{28}$ They considered these to be as sensitive as the measurement of static and dynamic compliance, but in general did not demonstrate any significant changes until the vital capacity became imparied.

The three remaining objective measurements found to be useful diagnostically reflected the systemic response. Fever and neutrophilia are both well-recognised features of positive "alveolar" responses to provocation tests, ${ }^{524262844}$ and both proved to have useful discriminatory value.

The mild but significant decrease in the number of circulating lymphocytes is an intriguing finding which has not been described previously, though Hargreave and Pepys observed that the proportion of lymphocytes decreased with positive tests, while that of the neutrophils increased. ${ }^{5}$ The discriminatory value of the lymphocyte changes was limited (sensitivity $52 \%$ ) and in only one instance did the lymphocyte count change significantly without the neutrophil count doing likewise. Its chief interest concerns its cause. Could the missing cells have migrated to the lung as a consequence, either of the antigenic challenge, or of the resulting immune/inflammatory response? In its acute phase, EAA is known to be characterised by an excess of pulmonary lymphocytes. ${ }^{4546}$ Geller and colleagues have recently reported low circulating lymphocyte counts in patients presenting with pulmonary hypersensitivity reactions to nitrofurantoin, ${ }^{47}$ as have Flaherty and colleagues in describing patients recovering from farmer's lung. ${ }^{48}$ In both reports it was the $T$ lymphocyte count which was reduced, thereby implying involvement of cellular immunological mechanisms. Alternatively, lymphopenia may have been a nonspecific consequence of the stress of the positive response, possibly as a result of increased corticosteroid secretion.

Auscultation, chest radiography, and the measurement of DLco or the subdivisions of lung volume may be expected to demonstrate significant changes only with relatively severe reactions. Such reactions could be readily identified anyway by the more sensitive monitoring observations described here. Only six of the 23 positive reactions (in five reactors) were associated with the development of clear-cut basal crackles and with only two of these did the Duco decrease significantly. The lowest total monitoring score of these six reactions was $5 / 8$, and the mean was $85 \%$ of the total possible-scores that comfortably identify unequivocally positive responses. Looked at another way, inhalation provocation tests that do produce crackles, significant falls in DLco, or radiographic changes are unnecessarily severe. This implies unnecessary distress to the patient concerned and, presumably, greater hazard.

It is interesting that the two strongest reactions occurred in the two patients with farmer's lung tested by the natural method of exposure. They disturbed samples of their own dry mouldy hay and straw in a challenge cabinet environment for 90 and 40 minutes respectively. This created considerably more dust than they were accustomed to occupationally and both reacted briskly to the first active test. In retrospect, shorter exposures would have been more appropriate. The avian challenges involved sequential increasing doses, the first of which was known to be safe. ${ }^{5}$ The bird fanciers were consequently better protected from unduly strong reactions, and so were less likely to demonstrate changes with respect to the less sensitive tests. Stronger reactions may not always be produced by greater challenge exposures, however, because the responsiveness of some subjects is limited. In these circumstances confirmation of positive reactivity may require that weak (though, for the individual concerned, maximal) responses are appropriately reproducible after further antigen and control challenges.

The device of assessing each provocation test by means of a total monitoring score enabled eight of 15 equivocal tests to be reclassified retrospectively as positive. The subjects concerned might consequently have been spared the dis- 
comfort and risk of further challenge exposures. The use of all six objective measurements found to be diagnostically useful was of course timeconsuming, and the question arises whether the routine use of all six would be cost-effective. In a sense, none is essential in evaluating the result of most tests because the subjective observations alone were shown to be adequate, being equally valid and rather more discriminatory. If, nevertheless, objective evidence is required to confirm the subjective findings, measurement of exercise minute volume is the most effective of the comparatively simple and easily available monitoring tests considered in this study. It is however the least convenient and the most time-consuming. More practical is the measurement of both body temperature and neutrophil count, one or the other of which is likely to change significantly with more than $90 \%$ of positive tests. The costeffectiveness of using any of the other objective tests in addition is marginal.

We are grateful to Dr P Green, Dr D Howes, and Dr H Armitage, Department of Haematology, Churchill Hospital, Oxford for carrying out the differential white blood cell counts, and to Dr EB Petersen of the Department of Physiology, Oxford University for supplying equipment for the heart challenge studies. The work was supported by grants from the Lauder Bequest (Oxford) and the Oxford Regional Health Authority (Teaching). This paper contains material from a thesis submitted to the University of London for the degree of Doctor of Medicine.

\section{References}

1 Pepys J, Riddell RW, Citron KM, Clayton YM. Precipitins against extracts of hay and fungi in the serum of patients with farmer's lung. Acta Allergol 1961; 16:76-7.

2 Reed CE, Sosman A, Barbee RA. Pigeon breeders' lung. JAMA 1965; 193:261-5.

3 Cohen HI, Merigan TC, Kosek JC, Eldridge F. Sequoiosis. A granulomatous pneumonitis associated with redwood sawdust inhalation. Am J Med 1967; 43:785-94.

4 Avila R, Villar TG. Suberosis. Respiratory disease in cork workers. Lancet 1968; 1:620-1.

5 Hargreave FE, Pepys J. Allergic respiratory reactions in bird fanciers provoked by allergen inhalation provocation tests. Relation to clinical features and allergic mechanism. J Allergy Clin Immunol 1972; 50:157-73.

6 Blyth W, Grant IWB, Blackadder ES, Greenberg $M$. Fungal antigens as a source of sensitiz- ation and respiratory disease in Scottish malt- $\stackrel{\vec{B}}{\vec{S}}$ workers. Clin Allergy 1977; 7:549-62.

7 Blackburn CRB, Green W. Precipitins against extracts of thatched roofs in the sera of New⿳亠口冋 Guinea natives with chronic lung disease. Lancet $\overparen{\Phi}$ 1966; 2:1396-7.

8 Friend JAR, Gaddie J, Palmer KNV, Pickering CAC, Pepys J. Extrinsic allergic alveolitis and $\vec{\circ}$ contaminated cooling-water in a factory machine. Lancet 1977; 1:297-300.

9 Faux JA, Hendrick DJ, Anand B. Precipitins to different avian serum antigens in bird fancier's lung and coeliac disease. Clin Allergy 1978; 8: 101-8.

10 Sakula A. Mushroom-worker's lung. Br Med $J_{\oplus}^{\circ}$ 1967; 3:708-10.

11 Faux JA, Wide L, Hargreave FE, Longbottom J, Pepys J. Immunological aspects of respiratory allergy in budgerigar fanciers. Clin Allergy $1971 ;$ 1:149-58.

12 Edwards JH, Baker JT, Davies BH. Precipitin test negative farmer's lung-activation of the $\overrightarrow{0}$ alternative pathway of complement by mouldyo hay dusts. Clin Allergy 1974; 4:379-88.

13. Pepys J, Jenkins PA. Precipitin (FLH) test in farmer's lung. Thorax 1965; 20:21-35.

14 Elman AJ, Tebo T, Fink JN, Barboriak JJ. Re-⿳亠二口犬 actions of poultry farmers against chicken anti-气 gens. Arch Environ Health 1968; 17:98-100.

15 Hearn CED, Holford-Strevens V. Immunological aspects of bagassosis. Br J Indust Med 1968; 25:윽 283-92.

16 Barboriak JJ, Fink JN, Sosman A, Dhaliwal KS 㱏 Precipitating antibody against pigeon antigens:in sera of asymptomatic pigeon breeders. $J \mathbf{L a b}$ Clin Med 1973; 82:372-6.

17 Riddle HFV. Prevalence of respiratory symptoms $x$ and sensitization by mould antigens among a윽 group of malt workers. Br J Indust Med 1974; 31:31-5.

18 Fink JN, Schlueter DP, Sosman AJ et al. Clinical survey of pigeon breeders. Chest 1972; 62:277-81.을

19 Salvaggio J. Diagnostic significance of serum precipitins in hypersensitivity pneumonitis. Chestoㅡㅡ. 1972; 62:242.

20 Jackson E, Welch KMA. Mushroom worker's lung. Thorax 1970; 25:25-30.

21 Eyckmans L, Gyselen A, Lauwerijns J, Cosemans N J, Wildiers J, Willems J. Pigeon breeder's lung. $\sigma$ Dis Chest 1968; 53:358-64.

22 Scadding JG. Lung biopsy in the diagnosis of diffuse lung disease. $\mathrm{Br}$ Med J 1970; 2:557-64.

23 Scadding JG. Coeliac disease and lung disease. Lancet 1971; 1: 968.

24 Williams JV. Inhalation and skin tests with exextracts of hay and fungi in patients with farmer's $\frac{\rho}{\mathbb{Q}}$ lung. Thorax 1963; 18:182-96.

25 Lunn JA, Hughes DTD. Pulmonary hypersensitivity to the grain weevil. Br J Indust Med 1967; 24:158-61. 
26 Channell S, Blyth W, Lloyd MM et al. Allergic alveolitis in maltworkers. $Q J$ Med 1969; 38:35176.

27 Avila R. Extrinsic allergic alveolitis in workers exposed to fish meal and poultry. Clin Allergy $1971 ; 1: 343-6$.

28 Warren CPW, Cherniack RM, Tse KS. Extrinsic allergic alveolitis from bird exposure. Clin Allergy 1977; 7:303-14.

29 Boyer RS, Klock LE, Schmidt CD et al. Hypersensitivity lung disease in the turkey raising industry. Am Rev Respir Dis 1974; 109:630-5.

30 Hargreave FE, Pepys J, Longbottom JL, Wraith DG. Bird breeder's (fancier's) lung. Lancet 1966; 1:445-9.

31 Warren CPW, Tse KS. Extrinsic allergic alveolitis owing to hypersensitivity to chickenssignificance of sputum precipitins. Am Rev Respir Dis 1974; 109:672-7.

32 Hendrick DJ, Faux JA, Marshall R. Budgerigarfancier's lung: the commonest variety of allergic alveolitis in Britain. Br Med $J$ 1978; 2:81-4.

33 Hendrick DJ, Davies RJ, D'Souza MF, Pepys J. An analysis of skin prick test reactions in 656 asthmatic patients. Thorax 1975; 30:2-8.

34 Ogilvie CM, Foster RE, Blakemore WS, Morton JW. A standardised breath holding technique for the clinical measurement of the diffusing capacity of the lung for carbon monoxide. J Clin Invest 1957; 36:1-17.

35 Comroe JH, Forster RE, Dubois AB, Briscoe WA, Carksen E. The lung. Chicago: Year Book Medical Publications, 1962.

36 Colton T. Statistics in medicine. Boston: Little, Brown and Co, 1974.

37 Lewis SM. The constituents of normal blood. In: Hardisty RM, Weatherall DJ (eds). Blood and its disorders. Oxford: Blackwell Scientific Publications, 1974:3-67.
38 Osgood EE, Brownlee IE, Osgood MW, Ellis DM, Cohen W. Total, differential and absolute leukocyte counts and sedimentation rates. Arch Intern Med 1939; 64:105-20.

39 Wintrobe MM. Clinical hematology. Seventh edition, Philadelphia: Lea and Febiger, 1974:1794.

40 Petersen ES, Vejby-Christensen H. Effect of body temperature on steady state ventilation and metabolism in exercise. Acta Physiol Scand 1973; 89:342-51.

41 Banaszak EF, Thiede WH, Fink JN. Hypersensitivity pneumonitis due to contamination of an air conditioner. $N$ Engl J Med 1970; 283:271-6.

42 Schlueter DP, Fink JN, Sosman AJ. Pulmonary function in pigeon breeders' disease. Ann Intern Med 1969; 70:475-70.

43 Warren CPW, Tse KS, Cherniack RM. Mechanical properties of the lung in extrinsic allergic alveolitis. Thorax 1978; 33:315-21.

44 Moore VL, Fink JN, Barboriak JJ, Ruff LL, Schlueter DP. Immunologic events in pigeon breeders' disease. J Allergy Clin Immunol 1974; 53:319-28.

45 Reed CE. Allergic mechanisms in extrinsic allergic alveolitis. In: Brent L, Holborow J (eds). Progress in immunology 1I. Amsterdam: North-Holland Publishing, 1974; 4:271-81.

46 Royal College of Physicians. Clinicopathological conference. Bird fancier's lung. Br Med J 1977; 2:1065-9.

47 Geller M, Flaherty DK, Dickie HA, Reed CE. Lymphopenia in acute nitrofurantoin pleuropulmonary reactions. J Allergy Clin Immunol 1977; 59:445-8.

48 Flaherty DK, Surfus JE, Chmelik F et al. Lymphocyte subpopulations in the peripheral blood of patients with farmer's lung. Am Rev Respir Dis 1976; 114:1093-8. 